\title{
COMMENTARY
}

\section{Academic Early Warning and Intervention Takes a Village}

Timothy P. Stratton, PhD, ${ }^{\mathrm{a}, \mathrm{b}}$ Beth K. Janetski, PhD, ${ }^{\mathrm{a}, \mathrm{c}}$ Mary E. Ray, PharmD, ${ }^{\mathrm{a}, \mathrm{d}}$ Mary C. Higginbotham, MA, ${ }^{\mathrm{a}, \mathrm{e}}$ Lisa Lebovitz, JD, MS, ${ }^{\mathrm{a}, \mathrm{f}}$ Beth A. Martin, $\mathrm{PhD}^{\mathrm{a}, \mathrm{c}}$

${ }^{a}$ Big 10 Academic Alliance Pharmacy Assessment Collaborative

${ }^{\mathrm{b}}$ University of Minnesota, College of Pharmacy, Duluth, Minnesota

${ }^{c}$ University of Wisconsin, School of Pharmacy, Madison, Wisconsin

${ }^{\mathrm{d}}$ University of Iowa, College of Pharmacy, Iowa City, Iowa

${ }^{\mathrm{e}}$ The Ohio State University, College of Pharmacy, Columbus, Ohio

${ }^{\mathrm{f}}$ University of Maryland, School of Pharmacy, Baltimore, Maryland

Corresponding Author: Timothy P. Stratton, University of Minnesota, College of Pharmacy, 1110 Kirby Drive, Duluth, MN 55812. Tel: 218-726-6018. Email: tstratto@d.umn.edu

Submitted May 25, 2021; accepted September 13, 2021; ePublished September 2021

Early intervention for students at risk of academic difficulty can be more effectively accomplished using a team-based approach that capitalizes on the expertise of many in a pharmacy education community. This commentary advocates for better integration of assessment professionals, pharmacy faculty, and student support services to capture academic, accountability, and behavior-related data that might signal student intellectual and/or behavioral challenges and manifest as marginal academic performance. Assessment professionals can assist with creating data dashboards/monitoring systems, recognizing trends within the data, refining formulas to identify at-risk students, and measuring the impact of interventions to determine which approaches positively and significantly influence outcomes. Effective early warning and intervention efforts take a village and should go beyond narrowly-focused attempts that fail to account for the complexity of students as individuals or acknowledge the multifaceted skill set students are expected to develop to become competent and responsible pharmacists.

Keywords: early warning, intervention, academic difficulty, assessment

\section{INTRODUCTION}

You sit down at your desk with a cup of coffee ready to start your day, but your enthusiasm quickly fades. An email from the experiential director, forwarded from one of the program's most reliable preceptors, reads: "My APPE student is really weak in their clinical knowledge and is struggling with timeliness. I'm not sure how they made it this far in the program given the deficiencies I am seeing." You had so much hope that recent curricular changes and content reinforcement would make a difference, but it clearly did not for this student. Frustrated, you wonder how this scenario could have been avoided. Might earlier intervention have helped, at the point when the student first started showing signs of struggling?

You consider whether student services personnel, course instructors, the experiential education director, and the student's faculty mentor, each committing to the student and contributing their expertise, could have teamed up to create an individualized support system that better addressed this student's challenges. Such teams are often ad hoc and organized with a slight variation of participants for each student facing a challenge. Imagine if the team created for this individual student's situation could be scaled into a formal system for student success. Such a system could impact multiple students, allowing for proactive intervention before temporary challenges or behaviors become intractable academic and professional difficulties.

We suggest that a holistic team that includes assessment professionals can become a formal network capable of responding to a single student's academic and/or professionalism issues in real time, while also systematically cataloguing and analyzing the experiences of all students who have difficulty to develop an inventory of effective support strategies. By identifying trends, a greater number of students can be helped at earlier points in their programs. This commentary advocates for better integration of assessment professionals, pharmacy education faculty, and student support personnel to capture data regarding student knowledge and behaviors that may signal future academic challenges. 


\section{Traditional Early Warning and Intervention}

Since the mid-1990s, pharmacy education researchers have sought variables that might help predict which students are at risk to encounter academic difficulty in pharmacy curricula. ${ }^{1-4}$ Early warning interventions proposed in the health sciences education literature range from pre-admissions identification by admissions offices, ${ }^{5-7}$ to building study skills through student services, ${ }^{8-10}$ to policy development by administrators. ${ }^{11}$ The search for pre-admission characteristics is encouraged by the Accreditation Council for Pharmacy Education (ACPE) Standard 17: Progression, calling for schools to connect admissions data as well as formative and summative assessment data with student academic performance. ${ }^{12}$ However, student academic difficulty may be a symptom of underlying challenges beyond intellectual capability or the inability to meet academic standards detectable only after matriculation. Education researchers in other health professions have found that either forced or voluntary departure decisions result from a cumulative effect of multiple stressors in students' academic, social, and/or external environments. ${ }^{13,14}$

Much of the higher education literature addressing academic difficulty attempts to narrow down and isolate the cause of academic difficulty to a single source inherent within the student. ${ }^{15}$ This approach minimizes the complexity of students as individuals and ignores the multifaceted skill set that pharmacy students are expected to develop to become competent and responsible practitioners. ${ }^{16}$ Academic difficulty is a manifestation of a complex interplay among multiple factors. Complex problems require solutions that are flexible and, perhaps, complex in their own right. Furthermore, given that many of the stressors contributing to a student's academic difficulty remain relevant after the student transitions to licensure and practice, those who learn to try multiple solutions, seek support services and build resilience early in an academic program may find the benefits lasting long after graduation.

\section{Identifying and Intervening Using Accountability Warnings}

Due to variations within and across pharmacy programs, individual programs should identify and select an optimal array of global and local risk factors that specifically challenge their students. While most programs have established intervention policies concerning sub-par academic performance within a course, it is equally important for programs to consider which non-academic accountability flags may also warn of future academic difficulty and warrant attention or intervention. Table 1 includes potential academic, accountability, and behavioral factors that can trigger an intervention with a student. To systematically collect and organize these data requires collaboration among multiple stakeholders to access, report, and reconcile the inputs. When these factors trigger an intervention, additional personal factors contributing to the student's behaviors such as mental/behavioral health, food and other resource insecurities, confidence, or learning disabilities may be identified and addressed.

Treating these factors or "flags" as data and incorporating them into one searchable database can help the student support team identify trends and provide a more holistic assessment of a student's capability for success. Further, demonstrating the relationship of accountability and behavior metrics to positive academic outcomes and successful professional behavior ${ }^{16}$ can consistently communicate to students, faculty, and staff the importance of integrating attitudes and behaviors with knowledge and skills in pharmacy education and in the profession.

\section{Data Access, Sharing, and Analysis}

Communication among faculty, course coordinators, student services staff, and assessment professionals is the next step toward identifying and supporting at-risk students. Multiple instances of the behaviors described in Table 1, in conjunction with poor grades on assignments or exams early in one or more courses, present a more complete picture regarding an individual student's difficulties than will grades alone.

However, awareness of data markers is not enough; acting upon these data is essential. A professional program cannot be so risk-averse or fearful of violating student privacy that they withhold information that, if shared, could lead to more engagement and intervention to benefit the student. The Family Educational Rights and Privacy Act (FERPA) should not prevent faculty and staff from communicating with one another in order to promote positive student outcomes. Instead of conceiving FERPA as a barrier, programs should feel an obligation to have such discussions early and often to help at-risk students thrive. A common misinterpretation of FERPA is that such conversations regarding disclosure of education records are prohibited when, in fact,

One of the exceptions to the prior written consent requirement in FERPA allows "school officials, "including teachers, within a school to obtain access to personally identifiable information contained in education records provided the school has determined that they have "legitimate educational interest" in the information. ${ }^{17}$ Formalizing the proposed student success team approach and transparently communicating to students what data may be examined for these purposes may also help reduce these concerns.

Systematically analyzing data and identifying factors that contribute to student difficulty can mean the difference between proactively supporting students at risk versus responding reactively only after a student is in crisis. In this 
proposed systematic model, student performance data from either a "homegrown" or commercially-available data monitoring and analysis system could be reviewed monthly by a program's assessment professional. Any concerns in a student's data would be brought to the attention of a program's academic progression or student affairs committee. The information regarding a specific student who is experiencing academic or behavioral challenges is then freely shared with each member of that student's support team, viewing concerns about a student through the lens of their own expertise: instructors focus on academic performance within a course; student services professionals connect students with collegiate resources such as tutors or institutional-level resources to assist with difficulties outside of class; faculty mentors evaluate accountability behaviors where intervention can be impactful. The student is then contacted by an appropriate member of the program's student support system for intervention, eg, Student Services, Dean of Student Affairs, the student's Academic Advisor, etc.

Unfortunately, the assessment professional is typically missing from this team; yet, assessment professionals can help bridge individual faculty/staff efforts and snapshots into an effective, collaborative system. By collecting, analyzing, and sharing student performance data, assessment professionals can assist with creating a data "dashboard" for each student, and create a comparator group using warehouse data collected from a particular cohort, the entire student body, or beyond. Assessment professionals can also help to recognize trends within the data, refine the formula to identify at-risk students, and measure the impact of interventions to determine which approaches positively and significantly influence outcomes.

Early warning systems are not foolproof; some medical education programs that implemented systems using both academic and non-academic warning flags reported instances where students who had no flags still encountered academic difficulties. ${ }^{18}$ Despite these shortcomings, the assessment professional could become the key to refining the collaborative early warning and intervention model by utilizing the identification and communication tools at their disposal. This model is appropriate in a culture that values information sharing and collaboration.

\section{Overcoming Challenges}

Implementing an early warning and intervention approach takes time and concerted effort. A culture of assessment must be established that incorporates consideration of disparate data points (including time), facilitates communication, and closes the feedback loop.

To a course coordinator, a poor exam score is an obvious trigger to identify a possible at-risk student; however, communication across all stakeholders remains essential. An effective tracking system starts with systematic collation of cues (data points) from a centralized collections process using a learning management system, exam software, or other tools. These data must then be examined regularly for patterns. Assessment professionals are particularly well-positioned to assist in this process, identifying signals that might indicate that a student's academic difficulties transcend a single course.

As noted above, these signals are then shared with the school's student progression or student affairs committee, and subsequently with an interdisciplinary group of faculty, staff and advisors who can intervene with at-risk students early. This interdisciplinary group can help craft written notification to the student (and to the student's academic advisor) utilizing compassionate verbiage so that the student feels encouraged and supported rather than targeted as a potential failure.

Closing the feedback loop for all team members is a frequently overlooked challenge in managing an early warning and intervention process. Feedback regarding the student's subsequent performance, including sharing communications between a student's advisor and faculty, must be purposefully provided to the entire team to assess an individual student's progress. Additionally, the team needs to check with faculty teaching the same cohort of students to monitor for performance trends of the class as a whole. Without this follow through, stakeholders lack the necessary reinforcement that the monitoring/intervention process matters, is feasible, sustainable, and is working.

A key to a successful system of monitoring and early intervention requires stakeholders to value and to commit to the process, requiring diligence even when the student seems resistant to early intervention or avoids such overtures entirely. These behaviors can often be a sign of embarrassment or shame, particularly for a historically high-achieving student. Sometimes students need to be led to the discussion table. And while the student who ignores opportunities for support can be frustrating and heartbreaking for all, such setbacks do not mean that all efforts to reach out to at-risk students are futile.

Despite the challenges and potential barriers outlined above, a systematic, holistic approach for providing student support has the largest potential for identifying at-risk students early, and hopefully assisting those students before they encounter insurmountable academic difficulties. 


\section{Call to Action}

Supporting students is increasingly complex in the face of strained resources. For a truly holistic approach that considers all factors impacting student performance and success, schools and colleges of pharmacy must recognize that no single person or collegiate unit may be able to identify and fulfill each student's needs. Every instructor who contacts a student due to a concerning exam score, or every preceptor who provides constructive rotation feedback is doing their part. Equally important is the student services staff member who notices a lack of organizational skills and teaches the student how to effectively use a calendar, the advisor who expresses concern about a non-responsive student, the school counselor who lends an ear or facilitates access to a food pantry, the student affairs specialist who arranges for a tutor, or the assessment professional who analyzes the data, evaluates student performance trends, and helps to ensure communication among all stakeholders for the purpose of promoting student success. All contribute to the goal of identifying at-risk students and intervening early on before the student struggles. It indeed takes a village of academic professionals to get academic early warning and intervention right.

\section{REFERENCES}

1. Houglum JE, Aparasu RR, Delfinis TM. Predictors of academic success and failure in a pharmacy professional program. Am J Pharm Educ. 2005;69(3): Article 43. Accessed May 5, 2021.

https://www.google.com/url?sa=t\&rct=j\&q=\&esrc=s\&source=web\&cd=\&ved=2ahUKEwiL6PCj57LwAhULG80 KHbMkCuYQFjABegQIAhAD\&url=http\%3A\%2F\%2Farchive.ajpe.org\%2Faj6903\%2Faj690343\%2Faj690343.p df\&usg=AOvVaw0CzaABGKH4QQJpIxT5wOEz

2. Meagher DG, Pan T, Perez CD. Predicting performance in the first-year of pharmacy school. Am J Pharm Educ. 2011;75(5): Article 81. Accessed May 5, 2021. https://www.ncbi.nlm.nih.gov/pmc/articles/PMC3142965/

3. Schlesselman LS, Coleman CI. Predictors of poor student performance at a single, Accreditation Council for Pharmacy Education-accredited school of pharmacy. Curr Pharm Teach Learn. 2011;3:101-105.

4. Alston GL, Lane D, Wright NJD. The methodology for the early identification of students at risk for failure in a professional degree program. Curr Pharm Teach Learn. 2014;6:798-806.

5. McCall KL, Allen DD, Fike DS. Predictors of academic success in a doctor of pharmacy program. Am J Pharm Educ. 2006;70(5): Article 106. Accessed May 5, 2021. https://www.ncbi.nlm.nih.gov/pmc/articles/PMC1637008/

6. Hanson DJ, Mort JR, Brandenburger T, Lempola A. Relationship of prepharmacy repeat course history to students' early academic difficulty in a pharmacy curriculum. Am J Pharm Educ. 2015;79(10): Article 154. Accessed May 5, 2021. https://www.ncbi.nlm.nih.gov/pmc/articles/PMC4749902/

7. Heldenbrand SD, Flowers SK, Bordelon BJ, Gubbins PO, O’Brien C, Stowe CD, Martin BC. Multiple miniinterview performance predicts academic difficulty in the PharmD curriculum. Am J Pharm Educ. 2016;80(2): Article 27. Accessed May 5, 2021. https://www.ncbi.nlm.nih.gov/pmc/articles/PMC4827578/

8. Johnson CW, Johnson R, Kim M, Mckee JC. Personal background preparation survey for early identification of nursing students at risk for attrition. J Nurs Educ. 2009;48(11):606-13. Accessed May 4, 2021. https://doi.org/10.3928/01484834-20090716-06.

9. Johnson CW, Johnson R, McKee JC and Kim M. Using the Personal Background Preparation Survey to identify health science professions students at risk for adverse academic events. Adv in Health Sci Educ. 2009;14:739-52. DOI 10.1007/s10459-009-9156-4. Accessed May 5, 2021.

https://www.researchgate.net/publication/24005420_Using_the_personal_background_preparation_survey_to_ide ntify health Science professions students at risk for adverse academic events

10. Villareal V, Martinez A. Assessing study skills in college students: A review of three measures. J Col Stud Devel. 2018;59(5):629-635.

11. Stegers-Jager KM, Cohen-Schotanus J, Splinter TAW, Themmen APN. Academic dismissal policy for medical students: effect on study progress and help-seeking behaviour. Med Educ. 2011;45(10):987-994.

12. ACPE. Accreditation Standards and Key Elements for the Professional Program in Pharmacy Leading to the Doctor of Pharmacy Degree. Chicago, IL: Accreditation Council for Pharmacy; 2015. Accessed May 4, 2021. https://www.google.com/url?sa=t\&rct=j\&q=\&esrc=s\&source=web\&cd=\&ved=2ahUKEwjFkOLJ27DwAhUDVc 0KHavzCdEQFjAAegQIAhAD\&url=https\%3A\%2F\%2Fwww.acpeaccredit.org\%2Fpdf\%2FStandards2016FINAL.pdf\&usg=AOvVaw1n2bjMqIy9RhbJzk3XC1z9

13. Jeffreys MR. Evaluating Enrichment Program Study Groups: Academic Outcomes, Psychological Outcomes, and Variables Influencing Retention. Nurse Educator. 2001;26(3):142-9.

14. Wells, MI. Dreams deferred but not deterred: A qualitative study on undergraduate nursing student attrition. Journal of College Student Retention: Research, Theory \& Practice. 2006-2007;8:439-456.

15. Schneider, M and Preckel, F. Variables associated with achievement in higher education: 
A systematic review of meta-analyses. Psychological Bulletin. 2017;143(6):565-600. Accessed August 30, 2021. https://www.google.com/url?sa=t\&rct=j\&q=\&esrc=s\&source=web\&cd=\&ved=2ahUKEwjmvvHb6JjyAhXPWc0 KHbMkBG8QFnoECCAQAw\&url=https\%3A\%2F\%2Fkeepteaching.unc.edu\%2Fwpcontent\%2Fuploads\%2Fsites\%2F1160\%2F2020\%2F07\%2FSchneider-Preckel-2017.pdf\&usg=AOvVaw3uU3DK08-IE3KdcsRD0KO

16. Kelley KA, Stanke LD, Rabi SM, Kuba SE and Janke KK. Cross-validation of an instrument for measuring professionalism behaviors. Am J Pharm Educ. 2011;75(9): Article 179. Accessed April 30, 2021.

https://www.ncbi.nlm.nih.gov/pmc/articles/PMC3230340/

17. U.S. Department of Education, Family Policy Compliance Office. The Family Educational Rights and Privacy Act. Guidance for Eligible Students. February, 2011. Page 3. Accessed May 3, 2021. https://www.google.com/url?sa=t\&rct=j\&q=\&esrc=s\&source=web\&cd=\&ved=2ahUKEwjt0vHcs67wAhVHK80 KHYMaDKkQFjAAegQIAhAD\&url=https\%3A\%2F\%2Fwww2.ed.gov\%2Fpolicy\%2Fgen\%2Fguid\%2Ffpco\%2 Fferpa\%2Ffor-eligible-students.pdf\&usg=AOvVaw3uvPakl2PbFQYpntTI3mwp

18. Yates J. Development of a toolkit to identify medical students at risk of failure to thrive on the course: an exploratory retrospective case study. BMC Medical Education. 2011;11(1): Article 95. Accessed May 4, 2021. https://bmcmededuc.biomedcentral.com/articles/10.1186/1472-6920-11-95 
Table 1. Example Academic, Accountability, and Behavioral Factors to Consider when Determining Academic Risk

\section{Academic Issues}

Low scores on key knowledge or skills assessment activities

Remediation needed for specific activities or a full course

Low scores on stand-alone or high-stakes assessments (eg, milestone exams, PCOA)

Declining academic performance per trend analysis/dashboard results

\section{Accountability Issues}

Late or incomplete application materials (eg, transcripts, documents)

Late or incomplete required trainings or documentation (eg, bloodborne pathogens, HIPAA, BLS and vaccinations)

Late participation in mandatory activities (eg, course registration)

Late, incomplete, or not completed assignments

Tardiness or absence from exams, in-class activities

Tardiness or poor participation during Introductory Pharmacy Practice Experiences

Nonresponsive to faculty/staff emails requesting a response

Consistent, repeated excused/unexcused absences

Analysis of accountability trends/dashboard results for students

\section{Behavioral Issues}

Disrespectful oral or written communications, other concerning behavior in either classroom or experiential settings

Low score on a critical thinking inventory or other affective domain tool/inventory, or demonstrated low self-awareness

.

Responsible for reporting

Course Coordinators

Course Coordinators

Assessment

Professional

Assessment

Professional 